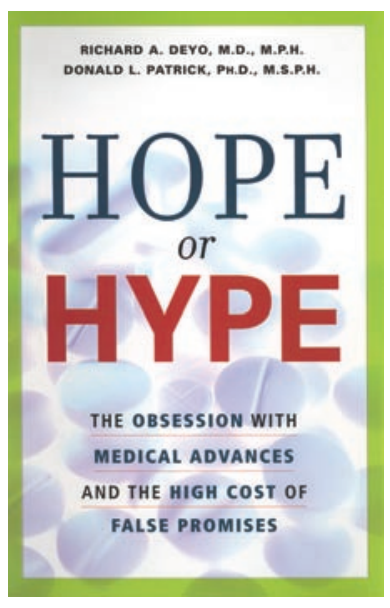

\section{Hope or hype}

The obsession with medical advances and the high cost of false promises

Richard A. Deyo and Donald L. Patrick

American Management Association. New York, New York, USA. 2005.

336 pp. \$24.95. ISBN: 0-8144-0845-1 (hardcover).

\section{Reviewed by Simon Chapman}

University of Sydney, Sydney, New South Wales, Australia.

E-mail: simonchapman@health.usyd.edu.au
। n March 2005, 3,000 doctors and scientists converged on Monte Carlo to attend the Anti-Aging World Conference, cosponsored by the American Academy of Anti-Aging Medicine. The delegates heard presentations from many branches of medicine, mostly dedicated to the pursuit of the unquestioned goal that medicine should do all it can to make cashed-up very old people in wealthy nations live longer or at the very least look younger. Each year, more and more of the world's health care budget is poured into efforts to stop elderly people dying sooner rather than a few months or years later.

There could be few more telling indictments of the moral malaise into which areas of modern medicine have been seduced, and it is safe to say that most of the conference delegates would find Richard A. Deyo and Donald L. Patrick's new book Hope or hype: the obsession with medical advances and the high cost of false promises a catalog of profanity. This is a scholarly, thoroughly referenced, and entirely accessible book that deserves to be read alongside two recent books that cover partially similar territory, although through far narrower lenses: Marcia Angell's The truth about the drug companies and Ray Moynihan and Alan Cassels's Selling sickness: how the world's biggest pharmaceutical companies are turning us all into patients.

The book begins by taking the reader through five broad myth-busting themes in medical advancement ("Don't we need lifesaving treatments?" "Medical innovations and American culture," "Why more isn't always better," "Why newer isn't always better," and "What we lose by uncriti- cal use of new treatments"). These set the foundational values for the second section of the book, which examines the main players propelling the imperatives for everonward medical advances: the pharmaceutical industry, the research community, the media, doctors and hospitals, and patient advocacy groups.

Part 3 of the book is a series of case studies of disabling treatments and surgery, ineffective and needless drugs, and the weight-loss industry. The final section is a collection of manifestos for all players with responsibilities in the mix: doctors, insurers, researchers, regulators, and consumers. Perhaps unsurprisingly, they offer no advice to the pharmaceutical industry. The authors' combined erudition in health policy analysis and in clinical work combine to take us from the very human needs, foibles, and vulnerabilities that cause patients to supplicate physicians for help through to the broader consequences, as when the values of medicine are confounded by the influence of other interest groups.

The head of the US National Cancer Institute, Andrew von Eschenbach, has caught the spirit of George Bush's all-conquering zeitgeist and challenged America to completely eliminate death from cancer by 2015 . In Sweden, it is official policy that the road death toll should strive to reach zero, not merely to fall. Single-issue health organizations often talk of research that might one day eliminate their diseases. The eradication of smallpox and the imminent departure of polio from the planet are evidently wonderful achievements. So why not conquer everything else, the thinking goes. Deyo and Patrick consider the values that propel this sort of thinking and the interests that stand to benefit from it.

Von Eschenbach's go-for-gold gauntlet draws on millennia of death-defying rhetoric among healers and doctors. This has been staged alongside countless replays of folkloric quests for fountains of youth and medicine's holy grail of defeating death. Deyo and Patrick's book is an encyclopedia of the manifestations of this quest in the last quarter of the twentieth century. If no one died from cancer, what would take its place? What would we die from if not from any of the diseases that medicine now tries to cure and public health policies try to prevent? And would this be progress?

If you scratch the surface of the human genome project, assumptions about eternal life are not hard to find. The director of the US Hastings Center, Daniel Callahan, wrote a humane and masterly book in 1998 titled False hopes: why America's quest for perfect health is a recipe for failure. He wrote of the deeply ingrained "pathology of hope" and its beneficiaries in the pharmaceutical industry. Together, these fuel exponentially rising health care expenditure in aging populations. Callahan's heretical proposal is that civil society should supplant medicine's present open-ended goal of prolonging life at all costs with a radical re-focusing on quality of life and the "compression of morbidity" during a decent life span. If Deyo and Patrick's book has a fault, it is its lack of international perspective on ways that different governments have sought to stem the tide of wasteful medical resource squandering. Except for this parochialism, it is a classic exposition that deserves a wide readership. 